\title{
Relaciones ganaderas entre Navarra y Guipúzcoa durante la Baja Edad Media y el comienzo de la Edad Moderna ${ }^{1}$
}

\author{
Transhumance and livestock farming between Navarre and \\ Guipuscoa during the Low Middle Ages and the beginning of the \\ Early Modern Ages
}

\author{
Álvaro Aragón RuANo \\ Universidad del País Vasco \\ alvaro.aragon@ehu.es
}

Recibido: $22 / 12 / 2014$

Aceptado: 10/03/2015

\section{RESUMEN}

Durante los siglos XII y XV grandes instituciones eclesiásticas navarras, como la real colegiata de Roncesvalles o la catedral de Pamplona, propietarios de extensas cabañas ganaderas, crearon una amplia red de seles y prados, que unía los pastos invernales de territorios como Guipúzcoa, Labourd, Baja Navarra, País de Soule o Béarn y los estivales de los Pirineos y la zona noroccidental navarra. El presente estudio analiza, en primer lugar, la evolución del uso y propiedad de los seles y zonas de pasto que dichas instituciones tuvieron en Guipúzcoa, entre los siglos XII y XV, a los que trasladaban en invierno sus bustos trashumantes. Si bien dichas instituciones fueron abandonando dichas prácticas, en algún caso perduraron más allá del siglo XVI. En segundo lugar, pretende analizar los conflictos surgidos por el paso entre territorios de rebaños que se trasladaban para su repasto y engorde.

Palabras clave: ganadería, vacuno, porcino, Guipúzcoa, Navarra, siglos XII-XVI.

\begin{abstract}
During the $12^{\text {th }}$ and the $15^{\text {th }}$ centuries big Navarre ecclesial institutions, such as the royal church of Roncesvalles and the cathedral of Pamplona, owners of big cattle herds, set up a large network of meadowlands, which put together winter meadows of Guipuzcoa, Labourd, Low Navarre, Soule or Béarn and the summer ones of Pyrenees and North-West of Navarre. The aim of this research is, firstly, to analyse the evolution of the use and property of the meadows and grasslands owned by the aforementioned institutions in Guipuzcoa, between the $12^{\text {th }}$ and the $15^{\text {th }}$ centuries, where their cattle herds moved to during the winter. Although they went leaving these customs, they exceptionally kept them in some cases beyond the $16^{\text {th }}$ century. Secondly, this essay would try to analyse the conflicts arisen as a result of the movements of herds between countries in order to graze and fatten cattle and pigs.
\end{abstract}

\footnotetext{
${ }^{1}$ Siglas: Archivo de la Catedral de Pamplona (ACP); Archivo Diocesano de Zaragoza (ADZ); Archivo General de Gipuzkoa (AGG-GAO); Archivo General de Navarra (AGN); Archivo Histórico de Protocolos de Gipuzkoa (AHPG-GPHA); Archivo Municipal de Hernani (AMH); Archivo Municipal de Oiartzun (AMO); Archivo Municipal de Ordicia (AMOr). Este artículo ha sido realizado en el marco del Grupo de Investigación en Patrimonio y Paisajes Culturales (Proyecto IT315-10), financiado por el Departamento de Educación, Universidades e Investigación del Gobierno Vasco.
} 
Key words: livestock, cattle, porcine, Guipuscoa, Navarre, $12^{\text {th }}-16^{\text {th }}$ centuries.

Sumario: 1. Introducción. 2. La catedral de Pamplona y sus seles en Guipúzcoa. 3. La real colegiata de Roncesvalles y su red ganadera. 4. Conflictividad ganadera en la frontera navarro-guipuzcoana. 5. Conclusiones.

\section{INTRODUCCIÓN}

Entre los siglos XII y XIV algunas instituciones eclesiásticas navarras, caso de la catedral de Pamplona o la real colegiata de Roncesvalles, establecieron una tupida red de seles y prados en los que albergar sus bustos de ganado vacuno ${ }^{2}$, tanto en verano como invierno. Gracias a la adquisición, por donación, trueque o compra, de numerosas propiedades tanto en el área pirenaica como en territorios costeros o cercanos a la costa, como Guipúzcoa, Labourd, Baja Navarra, País de Soule o Béarn, pudieron desarrollar una trashumancia estacional de largo recorrido, que les permitió contar con una extensa cabaña ganadera ${ }^{3}$. Dicha trashumancia se inició con la adquisición de dichas propiedades, por tanto, con importantes diferencias cronológicas según los casos; diferencias que, sin embargo, prácticamente no existieron en el final de dichas prácticas, pues ya para el siglo $\mathrm{XV}$, salvo contadas excepciones, habían desaparecido en lo que al territorio guipuzcoano se refiere. A pesar de los privilegios con los que contaban estas instituciones, esta actividad chocó pronto con el desarrollo de las villas guipuzcoanas, que habían iniciado un claro camino hacia la consolidación de sus propiedades y límites. Ello dio lugar a importantes conflictos y a cambios en la gestión de dichas posesiones, en muchos casos excesivamente alejadas de los centros matriz y de decisión, y con un papel complementario o secundario para sus haciendas, que pasaron del control directo al indirecto, para finalmente, en un largo proceso que va desde el siglo XVI al XIX, iniciar su desvinculación y venta.

Esa trashumancia se desarrolló desde los seles de invierno a los seles de verano de su propiedad, siendo de baja intensidad, pues el número máximo de cabezas de ganado desplazadas en cada caso no era superior a las 400, frente a los miles de cabezas de ganado vacuno y ovino que, por ejemplo, se desplazaban hacia el área francesa o el sur del reino navarro en el siglo $\mathrm{XV}^{4}$. Además, en esa trashumancia jamás se vieron implicados los montes comunales de las localidades de acogida, perfectamente blindados por las instituciones locales guipuzcoanas, que no permitían la entrada de

${ }^{2}$ La RAE define "sel" como "Pradería en que suele sestear el ganado vacuno". Diccionario de la lengua española [http://lema.rae.es/drae/?val=sel][consultado el 12 de enero de 2015]. También conocido como "cubilar" o "bustaliza", sobre todo en documentación navarra, en realidad, era un área, generalmente circular, poblada de árboles y prados, perfectamente delimitada por una serie de mojones, uno central y varios perimetrales, que contaba con una choza de materiales perecederos para el pastor y albergues y corrales para el sesteo estacional del ganado. Aragón Ruano, El bosque guipuzcoano, pp. 46. "Busto" = "Rebaño compuesto por vacas o bueyes pertenecientes a distintos dueños". Líbano Zumalacárregui, Paisaje rural, pp. 68-69.

3 Aparicio Rosillo, "La cabaña de las órdenes", pp. 13-26.

${ }^{4}$ Ibidem, 19-21; DíAz de Durana, "Economía ganadera", p. 54. Estos autores hablan, basándose en datos de 1434 , de 6.000 cabezas de ganado vacuno y 100.000 de ganado ovino. 


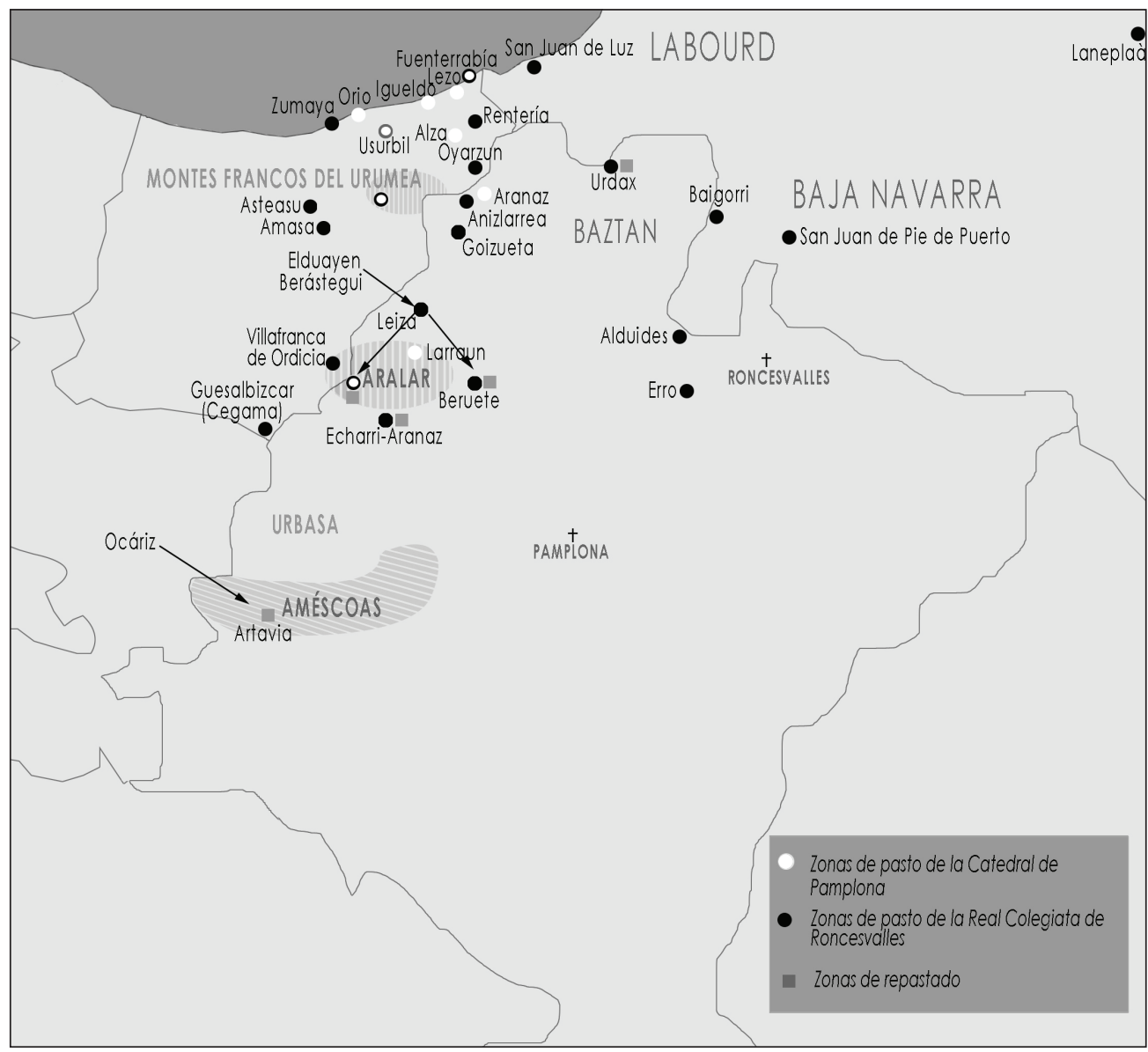

Fig. 1. Relaciones ganaderas entre Navarra y Guipúzcoa (ss. XII-XVII).

rebaños foráneos en sus comunales, imponiendo el pasto de "sol a sol", a no ser para su repastado, previo pago por los pastos, hierbas y aguas a disfrutar, y siempre que el abastecimiento de sus propias cabañas quedase garantizado ${ }^{5}$. Por último, a partir del siglo $\mathrm{XV}$, coincidiendo con un crecimiento demográfico y del número de cabezas, fue habitual el traslado de rebaños a otros territorios para su herbajado y repastado, tanto desde Navarra hacia Guipúzcoa como viceversa, así con ganado vacuno como porcino $^{6}$.

${ }^{5}$ Aragón Ruano, La ganadería guipuzcoana, pp. 32-56.

6 "Herbajar" = "Pastar el ganado". LíBAno ZumalacÁrRegui, Paisaje rural, p. 94. Por su parte, el Diccionario de la lengua española lo define como "Apacentar el ganado en prado o dehesa", "Pacer o pastar" [http:// lema.rae.es/drae/?val=herbajar][consulta realizada el 12 de enero de 2015]. "Repastar" = "volver a pastar" o "volver a dar pasto al ganado", es decir, engordar el ganado. Diccionario de la lengua española [http://lema. rae.es/drae/?val=repastar][consultado el 12 de enero de 2015]. 


\section{LA CATEDRAL DE PAMPLONA Y SUS SELES EN GUIPÚZCOA}

La catedral de Pamplona contó pronto con numerosas bustalizas ${ }^{7}$ y propiedades en suelo guipuzcoano, principalmente en Fuenterrabía y en los Montes Francos del Urumea, donde llegaría a contar con veintidós. Gracias a una escritura de donación de 1101, el rey Pedro Sánchez I de Navarra y Aragón concedía al monasterio de Leire algunas propiedades en la zona de San Sebastián y Hernani:

"Dono illam pardinam, quae vocatur Oroztegui cum suis terminis et apenditiis omnibus, terris cultis et incultis, pascuis, arboribus fructiferis et infructiferis et cum illa aqua, quae dicitur Hurhumea, que est pertinentia de Oroztegui”.

El año 1141 García el Restaurador, rey de Navarra, donaba a la catedral de Pamplona, en memoria de su esposa Margarita, todo lo que tenía en Igueldo, Urumea, Alza, Soroeta, Ariaz, Gorostiza Zaharra, Saberia Olatze, Zamilola y Aralar:

"totum quod in Iheldo Bizcaya habeo, cum tota sua pertinentia que mihi pertinet uel inuenire potuerint, et Hurumea similiter cum tota sua pertinentia, eta Alça et Soroeta cum suis pertinentiis, et todos meos cubilares quos in Ariaz inuenire potuuerint, et Gorostica Zaharra cum tota sua pertinentia, et Saueria Olatze eta Zamilola cum omnibus suis pertinentiis, et quicquid in Arelarre de meo inuenire potuerint"s.

Todos estos seles pasaron a partir de 1177 a manos de la chantría catedralicia, cuando el obispo Pedro París separó las posesiones de la catedral ${ }^{9}$. Un año mas tarde, en 1178, Sancho el Sabio confirmaba dicha donación, incluyendo toda una serie de terrenos y cubilares ${ }^{10}$ situados en la zona de Orio, Usúrbil y San Sebastián, que con el tiempo se convertirían en caseríos, casas solares y seles. En el caso de los situados en lo que luego sería la villa de Orio, su propiedad pasó en los siglos XV y XVI a manos de propietarios y poderes locales: en 1547 Juan Ortíz de Gamboa aparecía como dueño del caserío Lusarbe y de los seles de Bunioeta y Saria o Irasaroe, mientras que en 1550, su hijo, Pedro Ortíz de Gamboa, los vendió al concejo de Orio por 900 ducados; por su parte, Martín de Saria era dueño de Saria en 1504 y Juango de Aranduru de la casa Aganduru en $1511^{11}$ :

"Orio et Hieldo cum tota sua pertinentia, scilicet Loiçtaran, Erratzaual (Errezabal), Saria (Saria), Urdauide (Urdaira), Bunieta (Munioetazar), Dagandiburu (Aganduru), Lussarbe (Lusarbe), Iringuren, Irarue, Aenetzia, Lordibeguia, Loizta, Iuchita (Elutxeta?), Berarratza (Berarratza), Badotzularraburu, Amossorara, Zalburcaicoa, Iturriozagua et Hurumea, Arainiuar, Lastaola, Legarralde, Zuloeta, Ammunola, Mentauio, Anziz, Gierala, Muez, Macurssola, Guaragarze, Urtarzando, Izalegui, Aparren, Eua-

7 "Bustaliza" = "sel", "zona de pastos", "terreno dedicado a pasto". LíBAno ZumalacÁrregui, Paisaje rural, p. 62.

${ }^{8}$ Barrena Osoro, La formación histórica, p. 430.

9 Ostolaza Elizondo, "La organización eclesiástica”, p. 155.

10 "Cubilar" = "Campo", "Lugar donde acude el ganado a dormir, campo", es decir, sel o bustaliza. LíBANO ZumalacÁrregui, Paisaje rural, p. 89.

11 Alberdi LonBide, Orioko baserrien gidaliburua, pp. 12-14. 
liuia, Alza et Soroetha cum tota sua pertienentia et cum totas suas pescarias. Et in Ariatz: Goizeta-Iaznue et totos meos cubilares quos ibi habeo uel habere debeo. Et in Aralarre: Saueriolatze, Zamilola, Gorostiaga Zarra, Arriestarieta, Atelecotia, Ezquiaso Ataria, Barrunecoa, In Argoiena, cum tota sua pertinentia que pertinent uel pertinere debent." 12 .

Posiblemente, la catedral ya contaba con algún sel en el área de Fuenterrabía desde comienzos del siglo XIII, sin embargo, no fue hasta 1241 cuando comenzó a consolidar sus propiedades en Guipúzcoa. En dicha fecha, Pero Semenz de Sotés donaba a Santa María de Pamplona sus propiedades en Aparren y todas sus bustalizas de Urumea, Lerueta (Fuenterrabía) y Burdascar (Larraun) con todo su equipamiento, en atención a que Martín Pérez, arcediano de la tabla, le había embolsado 500 sanchetes y se había obligado a suministrarle durante su vida una ración canonical. El intercambio se hacía bajo la condición de que ningún sucesor del dicho donante pudiese "demandar en Apparren ni en sos bustaliçias en Hurumena et en Leuneta (Lerueta) ni el busto de Burdascar ni en l'ostillamienta, mays que sean del eglesia de Sancta Maria de Pamplona"13. Pocos años después, el 11 de noviembre de 1270, Alfonso X el Sabio recibía en Vitoria bajo su protección a la iglesia y cabildo de Santa María de Pamplona, con todos sus bienes, especialmente las casas, bustalizas y ganado que tenía en Guipúzcoa:

\footnotetext{
"recibo en mi guarda et en mi comienda la eglesia et y el cabildo de Santa Maria de Pamplona et todos sus bienes señaladamente casas et bustalizas et ganado et todas las otras cosas que ay en Ipuzcua tambien muebles como raiz et deffiendo que ninguno sea osado de fazer tuerto ni fuerça ni demas a ellos ni a ningunas de sus cosas"14.
}

Posiblemente, fue a partir de esta confirmación y reconocimiento, por parte de aquél a quien pertenecían jurisdiccionalmente aquellas tierras, cuando los rebaños de Santa María de Pamplona comenzaron a trashumar estacionalmente hacia Fuenterrabía, siempre entre sus propias bustalizas y propiedades; jamás en montes concejiles. Sin embargo, los problemas en Fuenterrabía comenzaron ya en el siglo XIII, más aún teniendo en cuenta que con la fundación de la villa en 1203 se produjeron una clara indefinición y solapamiento jurisdiccional y territorial, no resueltos hasta fines del XV. Debido a ello, las usurpaciones a las que le sometieron los vecinos de Fuenterrabía fueron continuas. Aunque no consta fecha en el documento, si bien se debe situar con posterioridad al año 1241, Miguel de Gaztelu, al final de sus días y tratando de evitar su excomunión, restituyó a San Miguel de Excelsis -y por tanto a la catedral- dos bustalizas de las que tenía en Fuenterrabía, concretamente las de Leyurieta (Lerueta) y Leizanavar, "que las tenia forçadas que non demande ninguna generacion que de mi sea..."15.

12 Barrena Osoro, La formación histórica, p. 431.

13 ACP, Libro Redondo, 92r.

14 ACP, B 10.

15 ACP, I Cantoris, 37, 32. Arigita y Lasa, Historia de la imagen, p. 222; Goñ Gaztambide, Catálogo, p. 122. Aunque este último autor sitúa dicho documento cerca de 1230 , esa fecha no puede ser correcta teniendo 
A partir del siglo XIV los problemas se recrudecieron en torno al disfrute y aprovechamiento de esas bustalizas, cuyo número se había ampliado, pues en la lista de las que tenía San Miguel de Aralar, y en su nombre la chantría -desde el año 1211, aunque Aralar estaba bajo jurisdicción de la catedral desde 1031-, junto a Fuenterrabía y Lezo -aldea perteneciente a la villa de Fuenterrabía-, aparecen ya quince, todas ellas en el monte Jaizquíbel. Según se denunciaba en 1371, muchas de esas bustalizas estaban ocupadas por gentes del rey de Castilla, es decir, por gentes de Fuenterrabía, concretamente, se mencionaban las de

“...Ayanssosi [Ayenssesi], Ayangue [Arague] (Arrangua), Odialaue [Odialcue] (Andialobe), Eyzcue (Exkulain), Oyondanaga, Aytarroz [Baycauiroz] (Gaztarrotz), Arcorrte (Arrobieta?), Leyuneta (Lerueta), Leyçanauar (Leizanabar), Erancin [Arançin] (Erantzin), Aznoz [Anoz] (Amaotz?), Murguyça (Mugarrieta/Mukitar) todas estas bustaliças son en Jazmendia aca al rio de Aguidya cabo Fontarrabia...E item otras tres bustaliças que auia a meas con Munguia (Murguía), Ayunguieça, Eyru-Çahapide estas son cabo Leço...".

Más aún, por el paso por el territorio y jurisdicción de Fuenterrabía hacia los mencionados seles, Fuenterrabía había comenzado a exigir anualmente al busto de la chantría de la catedral de Pamplona una vaca, cuando en realidad los seles habían pertenecido a San Miguel de Aralar sin que jamás se le hubiese exigido "premia

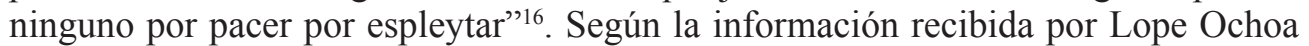
de Xavier el 26 de junio de 1371, clavero del chantre, y el bachiller Pascual Périz de Olleta, chantre y oficial, sobre los derechos que San Miguel de Excelsis tenía en las bustalizas de Fuenterrabía, Peru Adamiz, de cien años, manifestaba que desde que tenía catorce años trabajaba en el busto y anualmente todos los inviernos iba con las vacas, bueyes y ganado "a cabo Fontarrauia et soliamos andar en el termino clamado Jaç et los seles que se claman Muguinça, Adialoue, Gaiztanos, Leyurieta, Leyçanauarr", pastando con entera libertad, sin que nadie les molestase. Por su parte, Miguel Périz de Lacunza, de noventa años, Ochoa de Araiz, fraile y mayoral del busto de Roncesvalles, y Miguel Andía de Aguiregui, de ochenta años, confirmaron el testimonio del primero. Por su parte, Sancho Ezquerra de Arozpide, de 35 años, durante diez años vaquerizo en el busto de San Miguel y de la chantría, manifestaba haber estado durante ese período cuidando del busto en los mencionados lugares, "paçiendo las yerbas et bebiendo las agoas et que ninguno non los sacaua", y aseguraba que "quando el busto solia pasar auia en husso et costunbre los de Fontarrauia de prender un buey por la puent cada ayño et el prestanto hera i baca cada ayño el coal era de Sant Miguel sen prenda de ninguno por paz et por espleycar"17.

en cuenta la donación de Leuneta o Leyurieta (Lerueta) en 1241, ya mencionada; por tanto, hubo de ser redactado en una fecha posterior a dicha donación.

16 "Espleytar" = "disfrutar", "explotar". Líbano Zumalacárregui, Paisaje rural, p. 91.

${ }_{17}$ ACP, I Cantoris 37, 64 y 37, 168. ARIGITA y LASA, Historia de la imagen, pp. 314-316. En la lista aportada se ha decidido incluir, tanto la denominación que aparece en un documento sin fecha, datado entre los siglos XIII y XIV, como la que se relaciona en el documento de 1371 [entre corchetes y en cursiva], puesto que se producen ciertas variantes, además de la denominación o posible correspondencia actual (entre paréntesis). Agradecemos a Iosu Etxezarraga Ortuondo habernos informado sobre la existencia de dicha documentación. 
Por tanto, existía una trashumancia estacional que, sin embargo, en este caso concreto, no creemos que se pueda remontar más allá del siglo XIII, que es cuando las mencionadas propiedades pasaron a manos de la catedral de Pamplona. Dicha tradición pecuaria, sin embargo, no fue muy longeva, pues, como se ha podido comprobar, los problemas ya comenzaron a mediados del siglo XIV. Es este un período en el que las instituciones locales intentaron recuperar terrenos y aprovechamientos que les habían sido usurpados, o que pertenecían a instituciones particulares, tratando de hacerlas suyas o de tener una mayor participación, dentro de un proceso de consolidación y delimitación territorial que se prolongó desde mediados del siglo XIV hasta comienzos del siglo XVI. Así por ejemplo, en 1397 se emitió sentencia en el pleito entre San Sebastián y Fuenterrabía, quienes se acusaban mutuamente de destruir, talar, quemar y vender porciones que eran comunes a ambos en Jaizquíbel, obligando a ambas villas a explotar el bosque de forma igualitaria y sin mala fe, y en 1470 Fuenterrabía, Rentería y Oyarzun se comprometieron a respetar una sentencia arbitral sobre la división y partición de sus términos jurisdiccionales. Probablemente el crecimiento demográfico impelía a las poblaciones comarcanas a obtener, legal o ilegalmente, mayores espacios de explotación agrícola y ganadera que permitieran cierto desahogo económico y social ${ }^{18}$.

Ante tantos obstáculos y la lejanía de sus posesiones, lo que dificultaba su control y gestión, como ocurrirá en otros casos que posteriormente serán analizados, se optó por la gestión indirecta o delegada. El 25 de octubre de 1374 Pascual Périz de Olleta, chantre de Santa María de Pamplona, arrendó a Miguel Ochoa de Echarri, vecino de Larraun, su hijo Miguel Ochoa, su yerno Ximeno Miguel y a Miguel Oroizcain de Erros, los seles, prados y hierbas que San Miguel de Excelsis tenía en Echarri y Fuenterrabía, a cambio de mantener un busto de vacas y bueyes de la catedral de Pamplona, llamado Arunaelía ${ }^{19}$. Por el disfrute de dichos seles, hierbas y aguas, Miguel Ochoa de Echarri y sus consortes pagarían anualmente al chantre, el día de San Miguel (29 de septiembre) o en un plazo máximo de quince días desde esa fecha, 12 libras de carlines prietos de Navarra, y el día de Navidad 18 libras de manteca fresca, además de diezmos y primicias, quedando a su cargo los derechos que por dicho busto se debían pagar a los palacios de Murguía, Lazcano, Ugarte y a la villa de Fuenterrabía.

Posteriormente, el 18 de septiembre de 1390 Lope Sanz, abad de Meoz y procurador de Remón de Béarn, arcediano de la tabla, cedió los bustos de Guipúzcoa y Navarra a Íñigo Ibáñez, abad de Iríbas, Pero López de Lecumberri, alcalde de Larraun, Miguel Domínguez de Huici, arcediano del Val de Aybar, y don García de Aybar, canónigo del Valdonsella. A cambio de que Iñigo Ibáñez y sus consortes pusieran nuevo busto de vacas y bueyes en el partido de Larraun en nombre de la iglesia de Pamplona -concretamente en Burdascar-, el abad de Meoz dio perpetuamente al de Iríbar los seles, yerbas y aguas que tenía en Guipúzcoa, con especial mención a los de Urumea, Igueldo, Leizarán y Lerueta, y lo que le pertenecía en las montañas de Ardinçu y Ariatz, en Aralar, por 25 florines de oro de Aragón anuales, que debía

18 Crespo Rico, Colección Documental, I, pp. 93-100 y II, docs. 53-56.

19 ACP, I Cantoris, 37,167. Arigita y Lasa, Historia de la imagen, pp. 320-322. 
abonar cada día de Santa María de Agosto, el diezmo de becerros, es decir, de cada 10 becerros uno, y la manteca ${ }^{20}$.

En 1432, Martín de Abárzuza, chantre de Pamplona, envió a Santa María de Pamplona una carta sobre las bustalizas que tenía cerca de Fuenterrabía, con noticias de sus inmediatos sucesores. Para entonces los seles aparecen arrendados por el uso que se realizaba de ellos -encuadrados en el partido de Acular- durante el invierno y el verano y parece que en ellos ya no pastaban los bustos de la chantría. Dichos tributos se llevaban sin exigir durante bastante tiempo, puesto que uno de los anteriores chantres, que lo fue durante cuarenta años, había estado enfermo y no pudo hacer diligencia alguna. Cuando su sustituto quiso recuperar dichas rentas, ciertos vecinos de Fuenterrabía se negaron, les tomaron los seles y comenzaron a introducir su ganado a pastar en "...el termino clamado Jazmendia (Jaizkibel) y los seles llamados Muguiça, Adialone, Gayztarroz, Leynueta, Leyçanauar...”. Sin embargo, finalmente el concejo de Fuenterrabía restituyó a la chantría en su posesión ${ }^{21}$.

A pesar de ello, hemos de imaginar que las dificultades y ataques por parte de los vecinos de Fuenterrabía y del resto de Guipúzcoa continuaron, por lo que la chantría se dedicó, a partir de comienzos del siglo XV, a deshacerse de sus posesiones en territorio guipuzcoano. Fruto de ello, el 20 de septiembre de 1436, Diego García de Unzué, licenciado en decretos y hospitalero, donó y permutó al Monasterio de San Bartolomé de San Sebastián las heredades que la chantría tenía en Hernani y en Guipúzcoa a cambio de la pecha que el monasterio tenia en Arazuri y Adiós, localidades navarras, y 20 groses navarros. Las monjas hicieron carta de procuración para llevar a efecto el trueque reunidas en capítulo el 4 de enero de 1436. Por tanto, a partir de 1436 la mayor parte de las posesiones que le quedaban a la catedral de Pamplona en Guipúzcoa -con la excepción de Igueldo que llevaba disfrutando la catedral desde 1141, como hemos podido comprobar-pasaron al monasterio de San Bartolomé22.

Efectivamente, una escritura demuestra que entre 1488 y 1491, además de los cuartos decimales de Santa María y San Vicente de San Sebastián, se arrendaban los frutos decimales de la parroquia de San Pedro de Igueldo, igualmente perteneciente al arcediano de la tabla, patronato que perduró hasta el siglo XIX ${ }^{23}$. Poco después, en 1501 don Juan Ochoa de Olazábal, vicario de Santa María y San Vicente, así como el síndico procurador de la clerecía de estas parroquias, Miguel de Urresti, se sometieron a don Juan de Beaumont, recién nombrado arcediano de la tabla de la catedral de Pamplona, entregándole en señal de obediencia la cuarta de los diezmos de San Sebastián y su jurisdicción y firmando el contrato de arrendamiento de los bienes, por el cual los mencionados clérigos recibían en renta San Pedro de Igueldo "con su cargo de seruivio de diezmas", "reseruando para el señor archidiacono los seles de la dicha iglesia segunt e como fasta aquí se ha vsado", a cambio de 80 florines, siendo cada florín equivalente a 28 groses de Navarra ${ }^{24}$.

\footnotetext{
${ }^{20}$ ACP, Tabla 4.

${ }^{21}$ ACP, I Cantoris, 37, 87. Furundarena SAlsAmendi, "Hondarribiko toponimia", pp. 444, 521, 527-528 y 621 .

22 ACP, II Hosp. 188. Larrañaga Zulueta, Colección de documentos medievales, docs. 52 y 53.

23 InSAusti, "Situación canónica", pp. 305-306.

24 ADZ, Apelaciones 14-6. Agradezco esta referencia e información a Iosu Etxezarraga Ortuondo.
} 
En cuanto a los Montes Francos del Urumea, el 5 de diciembre de 1481 se estableció una concordia entre San Sebastián, Arano y Hernani sobre los veintidós seles que habían sido de los arcedianos de la tabla de la catedral de Pamplona desde el siglo XII. Ello significa que, en este caso, la trashumancia nunca pudo ser anterior a esa centuria. Para el uso y aprovechamiento de dichos montes, el 2 de agosto de 1379 se hizo concordia entre San Sebastián y Hernani, lo cual hace sospechar que por aquel entonces eran los vecinos de dichas villas quienes principalmente se aprovechaban de dichos seles. Para regularizar esas prácticas, en 1411 se hizo transacción entre San Sebastián, Hernani y el arcediano don Ximeno Aibar sobre el usufructo de los seles a cambio de 11 ducados navarros anuales.

Estos acuerdos tal vez revelan, como ocurrirá en el caso de Roncesvalles, cierta decadencia de los intereses ganaderos de la catedral de Pamplona en la zona, aunque no el final de la trashumancia de sus bustos hacia esta zona, pues, como posteriormente se analizará, alguno de ellos siguió visitando dichos montes en invierno, al menos hasta el siglo XVI. El 8 de mayo de 1461 se reunieron representantes de las villas, las cofradías de mareantes de Santa Catalina y la de San Nicolás, y los dueños de ferrerías que concretaron la proporción entre las villas, a razón de 6 para San Sebastián y 4 para Hernani. Finalmente, tras la conquista de Navarra, en 1516 el mencionado don Juan de Beaumont, arcediano de tabla, vendió a ambas repúblicas dichos seles en régimen de censo enfitéutico. El cabildo catedralicio contradijo la enajenación por haberse hecho sin su permiso, aunque finalmente, el arcediano León Goñi vendió de nuevo a San Sebastián y Hernani todo el derecho que podía tener sobre los veintidós seles del Urumea, quedando libres de cualquier pensión y reconocimiento; dichos seles eran "Aparrain", "Egurrola", "Sagarminaga", "Olaberriaga", "Urruçuno de suso", "Urruçuno de yuso", "Amunola de suso", "Amunola de yuso", "Uscalcue", "Sarasain", "Illarrasuain", "Anchista de suso", "Anchista de yuso", "Çuloeta", "Vacua", "Frías" (antiguo "Suaz" o "Fuaz"), "Çuniola", "Mendabio", "Gorostarbe", "Alsusta", "Legarralde" y "Lizarregui". En 1592 uno de los "Unçue" pasó a llamarse "Esteiza", y el de "Illarrasuain" a ser conocido como "Lasain"25. En 1534 Urnieta comenzó a reclamar su participación en los aprovechamientos de los Montes Francos del Urumea y finalmente en 1671 llegaron a la definitiva división de los mismos, quedando divididos en 9 partes, 4 para San Sebastián, 3 para Hernani y 2 para Urnieta ${ }^{26}$.

\section{LA REAL COLEGIATA DE RONCESVALLES Y SU RED GANADERA}

Roncesvalles fue una de las instituciones eclesiásticas que más propiedades tuvo en Guipúzcoa durante la Baja Edad Media: Zumaya, Aralar, Guesalbizcar, Oyarzun, Rentería o Fuenterrabía. La corona navarra mostró un intenso interés por afirmar el hospital, fruto de lo cual Sancho VI le concedió en 1176 exención de portazgo y pontazgo y libertad de pastos para su ganado en todo el reino, incluyendo los pastos de Alduides-Quinto Real, Andía, Aralar, Bardenas y el realengo guipuzcoano, todavía

25 Artola, Historia de Donostia-San Sebastián, pp. 55-56; Ayerbe Iribar, "Sobre el hábitat pastoril”, pp. 311-320.

26 AMH, C, 5, II, 2. 
bajo soberanía navarra. Gracias a ello, consiguió tejer una extensa red de bustalizas y derechos de pasto por el Pirineo navarro y aragonés, Las Landas, la Landa Bordelesa, las llanuras de Laneplaà, en la frontera entre el Béarn y Ultrapuertos, la Navarra atlántica y Guipúzcoa, combinando de esa forma los pastos de invierno y de verano; por ejemplo, a fines del siglo XIII contaba con alrededor de 90 seles en el área de los Alduides y $\mathrm{Erro}^{27}$. Curiosamente, coetáneamente se produjo la desvinculación parcial de sus propiedades en Guipúzcoa. Así el 30 de octubre de 1384 el prior y cabildo de Roncesvalles entregaron el monasterio de Santa María de Zumaya con todas sus tierras y pertenencias al concejo de Zumaya, a cambio de un censo enfitéutico de 440 maravedís anuales pagados cada San Miguel de Septiembre. El censo enfitéutico fue el medio de rentabilizar el patrimonio, aunque sometido a fuertes presiones por parte de la aristocracia y los concejos locales. Todavía en 1590 Rocesvalles ingresaba $585^{\prime} 6$ reales por los censos guipuzcoanos de Rentería, Alegría, Cerain, Villafranca de Ordicia, Cegama y Zumaya ${ }^{28}$. El hospital poseía desde al menos 1203 , como demuestra una bula de Inocencio III a la mencionada institución, la que posteriormente pasaría a ser la iglesia de San Pedro de Zumaya.

Coincidía en el tiempo todo ello con la donación múltiple de tierras en Amasa, Paquiace y Asteasu, por parte de Hernando de Blancafort al hospital. El patronato sobre Santa María de Zumaya no debió estar exento de tensiones pues en 1292 Sancho IV de Castilla realizó una nueva donación, acompañada de un buen número de heredades ${ }^{29}$. También consta desde 1494 hasta mediados del siglo XIX un censo enfitéutico perpetuo sobre la iglesia, hospital y bienes de Guesalbizcar, situados en Cegama y Segura. En el caso de Usúrbil, mencionado ya a fines del siglo XII, aunque la referencia más antigua se remonta a 1249, sobre la existencia de heredades de cultivo puestas a censo por la colegiata, fue también en el año 1388 cuando se produjo la firma de un convenio. No obstante, ya en el año 1330 el hospital de Roncesvalles y el mayoral de su busto, Lope Ibáñez de Aizcona, recibían sentencia favorable contra Gil López de Oñaz y otros hidalgos por el aprovechamiento de los pastos y bustalizas del hospital en el monte Andaza. Los mencionados hidalgos pretendían obligarles a pagar derechos, no por los pastos propios, sino por aquellos que consumían saliendo de dichos seles. Dicha sentencia les permitía pastar y aprovecharse libremente de los pastos, hierbas y aguas "dende saliendo de las sus bustalizas...que dende puedan alcancar", siempre y cuando respetasen el régimen "de sol a sol" y volviesen a sus albergues al final del día. Coetáneamente, otras instituciones religiosas se encontraron en la misma situación conflictiva. Así, en octubre de 1364 la orden del hospital de San Juan de Jerusalén eligió a los hermanos Miguel y Martín Pérez de Echarri, vecinos de Larraun, para que defendiesen judicialmente ante el obispo de Bayona los

${ }^{27}$ Miranda García, Roncesvalles, pp. 50-51 y 166; Aparicio Rosillo, "La cabaña de las órdenes", p. 15; Díaz de Durana, "Economía ganadera”, pp. 51-53.

${ }^{28}$ Miranda García, Roncesvalles, p. 172.

29 Ostolaza Elizondo, "La organización eclesiástica", p. 161; Miranda García, Roncesvalles, pp. 78 y 144. 
intereses de la orden en las bustalizas de Aranaz, Oyarzun, "Sorsaraiz" y Santiago de Fuenterrabía, ya que los vecinos de las villas del entorno entraban en ellas a pastar sus ganados y cortar sus árboles ${ }^{30}$.

Volviendo al año 1388, Miguel de Tobar, prior del hospital de Roncesvalles, y el señor Martín González de Alzaga o Achega pactaron un acuerdo relativo al aprovechamiento de los montes de Idia y Andaza, en Usúrbil, reservándose el hospital el segundo de los términos, desde Arsurondo hasta el río Oria, para su explotación ganadera y forestal, cobrando íntegro el diezmo del ganado, sin intervención del solar de Alzaga ni de la parroquia de San Salvador de Usúrbil, a cambio de la sexta parte de los ingresos obtenidos por el hospital en la venta de madera en dichos montes y del usufructo en Idia. A tenor de ello, los rebaños del hospital podían pastar libremente tanto en sus propios seles como en los del señor de Alzaga, sin que este pudiese introducir más bustos ${ }^{31}$. A partir de entonces, Roncesvalles inició una política de compra de terrenos. El 26 de octubre de 1419 se firmó una escritura de compraventa entre la colegiata y María Miguel de Reizta, vecina de Orio, por la que el prior adquiría el monte Andaza por 80 florines. Posteriormente, durante los siglos XV al XVIII el hospital realizó nuevas compras que completaron su patrimonio en dichos montes, hasta las desamortizaciones del siglo XIX. En 1577, la colegiata intentó la venta de los montes de Idia y Andaza, por medio de un censo enfitéutico por 12.500 ducados a Juan López de Aguirre y Alzaga, vecino de San Sebastián, aunque finalmente no se materializó por diversas cuestiones. La razón de esa venta, como en casos anteriores, bien pudiera ser las cuantiosas dificultades surgidas en torno a estas propiedades, difusamente delimitadas, las interferencias jurisdiccionales a la hora de fijar los límites concejiles y las diferencias en torno al aprovechamiento de los montes, aguas y pastos, al compás del desarrollo municipal ${ }^{32}$. Como manifiesta Isabel Ostolaza, razones de comodidad y factores políticos movieron a Roncesvalles a establecer un sistema censitario, delegando la administración de sus propiedades ${ }^{33}$.

En el caso de Oyarzun y su entorno, fue en el año 1389, un año después de la firma del convenio con el señor de Alzaga en Usúrbil, cuando Ayero de Ugarte y el hospital de Roncesvalles establecieron un convenio en torno a la titularidad y régimen de explotación de una serie de seles situados en la tierra de Oyarzun. En virtud de este pacto, Ayero de Ugarte cedió al hospital la propiedad completa de quince cubilares del Urumea y renunció a todo derecho sobre ellos: "Oquilagui de Suso y de Yuso", "Ireurgui de Suso y de Yuso", "Suerrin", "Ezpalaurgui", "Garayuri", "Aunçue", "Cuin", "Narvaçur", "Çuelqueçu", "Elqueta", "Çucola", "Oreineaga" y "Gaynarbe" o Añarbe, situados en la frontera entre Oyarzun, Rentería y Goizueta. Al mismo tiempo, reconocía poseer a medias con el hospital otro grupo de cubilares, cuya explotación ganadera y forestal se llevaría a cabo de mutuo acuerdo: "Aguinaga", "Idisso", "Ayncillos", “Alcoça”, "Lerrun", "Belliz", "Urpuru”, "Urpiondo", "Gaztelu", "Çarayo" y "Leçon", en la frontera entre Oyarzun y Fuenterrabía. Finalmente, las partes se comprometían a someterse al arbitraje que estableciesen los hombres

\footnotetext{
${ }^{30}$ VArios Autores, Los señores de la guerra, pp. 165-166; BARQUero Goñi, La orden de San Juan, p. 186.

31 VARios Autores, Los señores de la guerra, pp. 114-115 y 219-222.

32 Mutiloa Poza, Roncesvalles en Guipúzcoa, I, pp. 88-90 y II, pp. 5-8.

33 Ostolaza Elizondo, “La organización eclesiástica”, pp. 161-162.
} 
buenos de la tierra de Oyarzun sobre la propiedad de los cubilares de "Errengaguren" e "Issue". Posteriormente, los mencionados cubilares entre Fuenterrabía y Oyarzun se repartieron entre la colegiata y el palacio de Ugarte, en convenio firmado el 15 de septiembre de 1411 por Sancho de Meoz, prior del hospital y Amartingo de Ugarte. Roncesvalles acabó desprendiéndose de todos sus bienes en Oyarzun en 1571, por venta realizada al concejo de Oyarzun, aunque todavía en 1821 obtenía a título de diezmos 3.750 reales de vellón del cabildo eclesiástico de Oyarzun, 703'5 del de Fuenterrabía, 144 del de Lezo y 132 del de Rentería, que pagaba además un censo perpetuo de 181'5 reales de vellón por diez y medio seles en Añarbe, cuyo reconocimiento se escrituró en $1795^{34}$.

En Anizlarrea, que precisamente significa "prados numerosos", cerca de Oyarzun, Roncesvalles contaba con importantes propiedades desde el año 1270, cuando Lope Díaz de Haro, señor de Vizcaya, le donó la parte que le correspondía de los seles de Beracoyana, Errenga y Anizlarrea. En 1302 fue Beltrán de Guevara quien cedió a su hermana Estefanía las bustalizas que tenía en Aralar y Anizlarrea, con la condición de que a su muerte pasasen a la colegiata. En 1304 ésta permutaba con Martín Pérez de Eraso una hacienda en Sarasate por cinco bustalizas en Anizlarrea. Pero Ibáñez hacía en 1355 donación de todo lo que le pertenecía en Anizlarrea. Carlos II de Navarra otorgaba en 1366 dos suertes de montes en el mismo término, a cambio de 112 libras y 10 sueldos de renta, de la pecha de Atondo y "Aeça". Finalmente, en 1367 Roncesvalles compraba a Beltrán de Iracheta y Sancha Ruiz la octava parte de los montes y términos de Anizlarrea y Arano. Estos datos demuestran que Roncesvalles era consciente de las grandes posibilidades que se estaban abriendo para la cabaña ganadera en la vertiente cantábrica, por lo que se apresuró a asegurar sus derechos sobre los pastos invernales guipuzcoanos, especialmente ventajosos por los privilegios otorgados por los reyes castellanos; concretamente, por Alfonso XI en 1329, confirmando uno otorgado por Alfonso X, y en 1346, estableciendo la exención de peajes y portazgos para las primeras 10.000 cabezas de ganado que la colegiata moviera por la corona de Castilla ${ }^{35}$. Propiedades todas que, como en el caso de Andaza e Idia, mantuvo hasta las desamortizaciones del siglo XIX. Por tanto en este caso también los movimientos trashumantes no pueden remontarse más allá del siglo XIII. Como ocurriese en el caso de Fuenterrabía con la catedral de Pamplona, también parece que para finales del siglo XIV el interés de Roncesvalles por los pastos guipuzcoanos empezó a decaer. Ya en 1401 se arrendó buena parte de las hierbas de Anizlarrea y en 1406 se llegó a un convenio sobre derechos de pasto con los vecinos de Goizueta, en cuyo término se hallaba dicho espacio ${ }^{36}$.

En cuanto a la presencia de Roncesvalles en el Aralar guipuzcoano, al parecer, el origen de la propiedad de dichos seles por parte de la colegiata arranca de una donación que hizo Enrique II de los seles de Beasquin (Beaskin), Fagabe y Yaraza (Igaratza) a su vasallo Don Beltrán de Guevara, quien los legaría en testamento en

34 Varios Autores, Los señores de la guerra, pp. 222-226; Mutiloa PozA, Roncesvalles en Guipúzcoa, I, pp. 100-101; Larrañaga Zulueta, Colección Documental, I, doc. 38.

35 Ostolaza Elizondo, "La organización eclesiástica", pp. 162; Mutiloa Poza, Roncesvalles en Guipúzcoa, III p. 7; Miranda García, Roncesvalles, pp. 70, 78, 106 y 111.

${ }^{36}$ Miranda García, Roncesvalles, p. 145. 
1302 a su hermana Estefanía "por los días de su vida, y después d'ellos a dicho real convento" de Roncesvalles. Aunque la colegiata alegaba que su presencia en la sierra era inmemorial, los primeros conflictos con los vecinos de la misma se documentan en 1386 -en esto coincide con el resto de casos descritos- cuando vecinos de Amézqueta atacaron el ganado de la cabaña o busto de Fraidelía, propio de Roncesvalles, que motivó sentencia del provisor de Pamplona, ordenando a los vecinos la devolución de lo usurpado.

A partir del siglo XV, los conflictos con los integrantes de la recién creada Mancomunidad de Enirio-Aralar en 1409 fueron ya continuos, al no estar amojonados los seles, y continuaron hasta que, previo compromiso de las partes para proceder a un pacífico pasturaje, se dictó determinación arbitral en 1452 entre Roncesvalles y la villa de Villafranca de Ordicia, como representante de Amézqueta, Abalcisqueta y Zaldivia, por la que se reconoció la posesión de cada uno de los seles. La sentencia permitía a Roncesvalles albergar 350 cabezas de ganado vacuno en su busto de Fraidelía, pudiendo pastar por toda la sierra de Aralar, y reconocía como seles de Roncesvalles a "Yheraça", "Yheraça arralde", "Yheraça elorriandiadaua", "Hayaçio", "Otabeaça", "Gorostiaga", "Beasquin", con los seles de "Beasquin", "Beasquinarte", "Onçeburu de suso y yuso", el término de "Fagabe" con los seles de "Fagabe", "Fagabe behierdisaroea", "Fagabeveicegui saroea", "Çuqarça saroea", "Fardal", "Situeta ondarra", "Mauruacarizolaça", "Loyolasaroea", la mitad de "Ydoybelçibar", "Orocoz de yuso", "Arpeloa", "Fardelus Ausurdia" y "Urrestoui". Para Zaldivia quedaban "Arviçeta" ("Vidasola" y "Olade yuso") y "Munipieguia", mientras que "Mendiaras" quedaba para los parcioneros de Aralar. Para Amézqueta eran "Fardelus", "Latosa", "Latosa arcaraya", "Alçolaça" y "Olarca". Se establecía que los vecinos de Villafranca, Amézqueta y Abalcisqueta no matasen "...ganados algunos bacunos del busto de Fraydelia..." y los frailes del convento de Roncesvalles "...ganados granados ni menudos..." de dichas villas, sino que los prendasen e hiciesen pagar calumnia: el ganado vacuno 8 blancas, el ganado rocinar 12, el ovejuno y caprino 3 , y el porcino 4. Por último, se establecían por terrenos comunes los de "Leyçasobea", "Otocorzayna", "Otocor", "Guiberriça", "Berraga leyçeadaua", "Catuxpea", "Esquiçu" y "Merindaras" (Mendiaras).

Apenas duró dos siglos la presencia de Roncesvalles en sus seles de Aralar, pues ya en el siglo XVI los gozaba Villafranca de Ordicia en calidad de censo enfitéutico, pagando 14 florines de oro ( 10 ducados y 2 reales) como reconocimiento de su dominio directo. A causa de la irregularidad del pago de dicho censo, la colegiata demandó a comienzos del siglo XVII y en 1635 a dicha villa ante el Corregidor guipuzcoano pidiendo la restitución de los seles, y así se ordenó en 1637. No obstante, en 1645 la colegiata volvió a otorgar otra escritura censal a favor de la villa por la misma cantidad. Villafranca siguió disponiendo de los seles; sin embargo, la dificultad del pago del censo comprometido le llevó en 1658 a arrendar a Ataun el derecho a pastar con sus ganados en ellos y a concertar en 1663 con todas sus antiguas vecindades (salvo Amézqueta) un compromiso de uso y disfrute de aquellos por un montante global de 400 ducados de plata, y los 10 ducados y 2 reales del censo anual pagaderos en su correspondiente turno. Pero nuevos impagos por parte de la villa movieron a Roncesvalles a reanudar la batalla legal por la recuperación de sus seles, mientras con- 
solidaba su relación con Amézqueta, cabeza de la Unión de Bozue mayor, que no se había avenido a suscribir el contrato de 1663 . Habiéndose dado sentencia a su favor en 1713, el 7 de abril de 1717 Roncesvalles vendió sus seles y términos a la villa de Amézqueta por 2.600 pesos, que tomó posesión de los mismos el 27 de septiembre de 1721. Roncesvalles dejaba así su presencia secular en Aralar ${ }^{37}$. Por tanto, en el caso de Aralar, la trashumancia de los bustos de Roncesvalles se mantuvo entre los siglos XIV y XV, pero para el siglo XVI ya eran los bustos y rebaños de las villas guipuzcoanas en torno a la sierra quienes disfrutaban de dichos seles, a pesar de permanecer en manos del hospital.

A partir del siglo XVI, a pesar de la venta, desvinculación o arrendamiento de muchas de sus propiedades, Roncesvalles siguió llevando sus rebaños a tierras guipuzcoanas. En 1533 la colegiata denunciaba a Bernat Cruzat, fiscal y arrendador de las tablas navarras, por la posesión de meter y sacar del reino de Navarra, especialmente hacia Guipúzcoa, sus vacas y ganados a herbajar y vender libremente. Pedro de Urrutia, sastre y testigo de Goizueta, siendo teniente de las tablas de Goizueta y Anizlarrea, manifestaba que hacía un tiempo vio que pasaron más de 60 becerros a Oyarzun y se vendieron a unos "alamanes" que pasaban por Articuza y Urdaide. Según su testimonio, durante el mes de septiembre, los carniceros y carnicerías de Guipúzcoa se desplazaban a Anizlarrea a comprar vacas de la colegiata y otras partes, y las pasaban a Guipúzcoa, sin pagar derechos; uno de los testigos aseguraba que en Anizlarrea se vendieron en una sola venta 45 vacas a los carniceros de San Sebastián.

Roncesvalles llevaba sus bustos y yeguas a herbajar a los montes de su propiedad situados en Andaza, en Usúrbil. Bernat de Baygerr o Baigorri, vaquerizo y guarda de las vacas de Roncesvalles, desde hacía cuarenta años, quien había estado quince años ausente de la guarda, trabajando en la ferrería de Articuza, propiedad del señor de Zubizar, llevaba los últimos diez custodiando el busto de Auso Moraldea. En invierno pasaba las vacas novillas y becerras del busto a Andaza a herbajarlas, mientras que en verano las volvía a pasar hacia Navarra. En el momento de la declaración, el mencionado busto se hallaba herbajando en los términos de Hernani y San Sebastián, en los Montes Francos del Urumea, donde compraban los pastos, yerbas y agua. Por su parte, los bustos de Albetielía y Enfermerelía, con sus mayorales y guardas, 5 o 6 años atrás, pasaron en invierno a herbajar a Labourd por el puerto de Maya, vendiendo allí muchos novillos, a San Juan de Pie del Puerto y a Beruete, y volvieron por primavera ${ }^{38}$. Durante todo el siglo XVII, los bustos de Roncesvalles, Baztán y Baigorri, pastaban en invierno en Anizlarrea, bajo el cuidado de guardas y vaqueros asalariados, teniendo por costumbre entrar en los montes de Oyarzun, si bien los conflictos con los vecinos y concejo de la localidad guipuzcoana fueron numerosos ${ }^{39}$.

\footnotetext{
${ }^{37}$ AMOr, Unión Aralar y Enirio, Libro 1, Exp. 4. Ayerbe Iribar, "La Unión o Mancomunidad”, pp. 13-16.

${ }^{38}$ AGN, Procesos de la Corte Mayor, 186.

${ }^{39}$ AMO, A, 1, 1, 2; AHPG-GPHA, 3/2168, ff. 44r-45v y 3/2171, ff. 119rv.
} 


\section{CONFLICTIVIDAD GANADERA EN LA FRONTERA NAVARRO-GUI- PUZCOANA}

La frontera navarra con Guipúzcoa se convirtió en área de continuo conflicto a partir del siglo XIV, siendo conocida como "frontera de los malfechores", dando lugar a la formación de hermandades, sobre todo en períodos de guerra abierta ${ }^{40}$. Los robos de ganado fueron numerosos, obligando a intervenir a las autoridades de ambos reinos. Los cuatreros guipuzcoanos y navarros, en la mayoría de los casos originarios de los pueblos fronterizos, concretamente del Goierri, Cinco Villas y Basaburua, actuaron sobre todo en los valles de Leizarán, Araiz, Larraun, Aranaz y Burunda ${ }^{41}$. Posteriormente, con la conquista e incorporación de Navarra a la Corona de Castilla, los enfrentamientos disminuyeron ostensiblemente y únicamente se produjo algún conflicto puntual y localizado en zonas concretas. El 27 de septiembre de 1519 los comisionados de Navarra y Guipúzcoa sentenciaban acerca de las prendarías ${ }^{42}$ que se venían realizando en los montes de Aralar y Endreceras y las penas a pagar por ellas, además de sobre el amojonamiento de los términos limítrofes de Alleco y Errenaga; quedaban exentos del convenio los rebaños de la colegiata de Roncesvalles. En primer lugar, se daba comisión a Juan Martínez de Andueza y al comendador Ochoa Álvarez de Isasaga, poderhabiente de Guipúzcoa, para que junto con los representantes de las villas navarras y guipuzcoanas subiesen a la sierra e hiciesen el apeamiento. En segundo lugar, se prohibían las prendarías de ganado. En tercer lugar, se ordenaba compensar las prendarías y "carneamientos" realizados hasta la fecha. Por último, se ordenaba que fuesen devueltas las bestias prendadas a cada una de las partes. En carta partida establecida el 31 de marzo de 1520, a pesar de que Guipúzcoa propuso que no se penase ni prendase en rebaños de menos de 15 cabezas, se fijó finalmente una pena de 1 real nuevo de plata por cabeza de ganado mayor prendada, y de 6 cornados ( 3 maravedís) por cada cabeza de ganado menor ${ }^{43}$.

En 1531 Bernat Cruzat, arrendador de las tablas navarras, denunció a los vecinos y concejos de Berástegui y Elduayen por no pagar los correspondientes derechos de peaje y saca del ganado vacuno que introducían anualmente para herbajar y vender, por lo cual el año 1530 los tablajeros y dezmeros del reino de Navarra les habían hecho prendas de sus bustos y ganado. Juan de Gorostizu, mayoral de los bustos de Berástegui y Elduayen, denunció a Martín Arano de Zavalo, teniente y peajero de las tablas en Leiza, en nombre del arrendador general entre 1529 y 1531, Joan de Eslava, vecino de Tudela, por haberle prendado unas 250 vacas. Martín Arano de Zavalo

40 Álvarez Morales, “La Hermandad de Vitoria”, pp. 341-347; Ayerbe Iríbar, "La hermandad de frontera", pp. 369-386; Díaz DE Durana, "La frontera de los malhechores”, pp. 171-205; Mugueta Moreno, "Las hermandades navarras", pp. 421-428 y "Acciones bélicas en Navarra”, pp. 49-78; Orella Unzue, "La Hermandad de Frontera", pp. 463-492; ZABALO ZABALEGI, La administración, pp. 312-315 y "El acoso de guipuzcoanos y alaveses", pp. 53-109.

41 Ciérbide Martiarena, "Conflictos fronterizos”, pp. 449-470.

42 "Prendar" = "Tomar una prenda como garantía de una deuda o como pago de un daño recibido". Diccionario de la lengua española [http://lema.rae.es/drae/?val=prendar\%C3\%Ada][consultado el 12 de enero de 2015]. En el contexto en el que estamos, significaría tomar prendas -en muchas ocasiones las propias resescomo garantía por los daños realizados por el ganado.

43 AGG-GAO, JD IT 4022, 3 y 9. 
alegaba que Gorostizu debió haber manifestado dichas vacas al entrar en Navarra y tomar guía para andar por todo el reino. Los vecinos de Berástegui y Elduayen llevaban a herbajar sus ganados al lugar de Beruete en el reino de Navarra, donde compraban las hierbas, es decir, pagaban por el herbaje, saliendo y entrando por el puerto de Leiza. Los acusados se comprometieron finalmente a pagar al tablajero la pena que estableciese el consejo de Navarra, a cambio de que las reses les fuesen devueltas. Los testigos presentados por ambos concejos, mayoritariamente vecinos de Leiza, declaraban que los de Berástegui y Elduayen siempre habían estado en posesión de la libertad de pasar los ganados sin pagar peaje, sacar o manifestar el ganado.

Los testigos de Beruete, concretaban que los de Berástegui y Elduayen llevaban allí sus ganados a herbajar, pagando la hierba al concejo, desde hacía cuarenta años. Así por ejemplo, Joan de Erala, vecino de Eulate, declaraba que, siendo su padre tablajero, vio muchas veces como desde la provincia de Guipúzcoa, Álava y fronteras de Castilla se traían vacas, bueyes, yeguas y puercos a herbajar y cuando entraban manifestaban en Eulate los ganados que traían. Según su testimonio, desde hacía cuarenta años un vecino de Ocáriz iba a Artavia con sus vacas, bueyes, yeguas y puercos a herbajar y lo mismo se hacía en el resto de tablas de las Améscoas (Larraona, Aranarasti, Zudaire, Gollano y Baquedano), pagándose 2 groses por cada cabeza de ganado mayor y media tarja por cada cabeza porcina. Por último, recordaba que hacía seis años, esto es, en 1525, se trajeron muchos puercos de Álava y Guipúzcoa a los montes de las Améscoas.

Como se ha podido comprobar, tanto en el caso de Berástegui y Elduayen como en el de Ocáriz, los testimonios coinciden en señalar que el traslado de rebaños desde la zona vasca a la navarra se había iniciado hacía cuarenta años, esto es, en los años noventa del siglo XV, lo cual es lógico si se tiene en cuenta que la mencionada frontera de los "malfechores" no fue pacificada hasta mediados del siglo XV, gracias a la formación y acción de las hermandades de frontera. Por tanto, la pacificación de la frontera en la segunda mitad del siglo XV, consolidada con la conquista de 1512, ayudó a iniciar y desarrollar, con garantías y sin sobresaltos, el traslado de los rebaños entre territorios, hasta hacía poco beligerantes, en un momento en el que además, a partir de mediados del siglo XV, se estaba produciendo un crecimiento demográfico y de la cabaña ganadera en territorios como Álava y Guipúzcoa. Ese crecimiento obligaría a algunas localidades, con cortas extensiones territoriales o de pastos, a buscarlos en jurisdicciones cercanas, con una menor presión pecuaria y una mayor riqueza forestal ${ }^{44}$.

La introducción de productos en Navarra estaba regulada por las denominadas “Ordenanzas de la imposición", establecidas en Pamplona el 7 de junio de 1529. En primer lugar, en caso de producirse una compraventa de ganado vivo vacuno, ovejuno, cabrón, puercos o cabras u otro ganado comestible, además de ser manifestada, el vendedor debía pagar 20 sueldos y 12 dineros, y el comprador declarar de quién lo había comprado y el precio; en caso contrario, se establecía la pérdida del ganado y una pena de 10 libras por vegada. En segundo lugar, cualquiera que trajese ganado de fuera del reino debía manifestarlo en el primer lugar de entrada al reino, obteniendo cédula o pasaporte, y pagar una única vez 12 dineros por cada libra; siendo así, podría

\footnotetext{
${ }^{44}$ Aragón Ruano, La ganadería guipuzcoana, pp. 46-47.
} 
vender el ganado libremente en la primera vegada, bajo pena de 20 libras en caso de no manifestar la venta. En tercer lugar, cualquiera que vendiese algo a extranjeros debía manifestarlo al comisario o al diputado. En cuarto lugar, debido a la extracción fraudulenta de vino, sin el correspondiente pago de derechos, que se realizaba en las merindades de Tudela y Estella, se obligaba al vendedor a que retuviese en su poder el derecho de la saca y lo pagase el mismo día al guarda, so pena de perder el vino. En quinto lugar, para que los mercaderes y mulateros anduviesen libres por el reino, ningún oficial debía osar prendarles las bestias o acémilas, salvo si fuesen deudores por sí o fiadores por otro. En sexto lugar, no se debía intentar cobrar más derechos de los debidos en animales vivos o muertos ni en mercadurías. En séptimo lugar, quedaba prohibido extraer producto alguno del reino a excepción del trigo, pagando 6 dineros por cada libra. En octavo lugar, quien no respetase dichas ordenanzas, sería encarcelado. En noveno lugar, todo ganado que entrase a pastar en las Bardenas o en cualquier lugar del reino debía dar cuenta al comisario de la primera villa por donde entrase. Por último, los comisarios debían respetar el capitulado, bajo pena de 50 libras.

Además de estas ordenanzas, el régimen de pasto de los ganados extranjeros venía regulado por una serie de capítulos forales, bajo el epígrafe común de "De las pasturas de los ganados ca no deben pascer o pasar e sean fuera del reyno o del reyno en los terminos de qualquiere lugares o sotos del reyno de navarra del señor rey". El artículo número 12 establecía que:

"Todo ganado granado o menudo que verna de fuera del reyno a pacer las yerbas deste reyno de Navarra sin manifestar o sin licencia del rey pierde el dicho ganado e si entrare con licencia o manifestado o arrendado o comprada la yerba y pague aquella que seran abenidos con el rey o quien su cargo o poder tubiese y en otra manera pierda el dicho ganado como dicho es la metad sera para el señor Rey y la otra mitad para los comisarios o arrendadores que son o seran en aquel tiempo".

Por su parte, el artículo número 13 establecía que

"Item por razón que en las entradas de los dichos ganados se hazen muchos fraudes y engaños en especial en el numero de los rebaños por defraudar y furtar los derechos reales ni pagar aquellos non vsando mil cabeças o mas sera que el tal rebayno asi mismo en el ganado granado trezientas o quatrozientas cabeças ser rebaño por se frenar los tales fraudes y engaños ordenamos y mandamos que el numero del ganado granado sea cient cabeças con sus crianças y aquel sea llamado rebaño y el numero del ganado menudo sea quinientas cabeças con sus crianças y que sea llamado rebaño el tal y no más" ${ }^{45}$.

Todavía en 1534 seguía abierto y sin resolver el conflicto entre las universidades de Berástegui y Elduayen y el fiscal sobre la paga de peajes de los ganados que entraban a herbajar al reino de Navarra. Juan de Andueza, señor de Andueza, aseguraba que Berástegui y Elduayen y otros pueblos de Guipúzcoa acostumbraban en verano a introducir en el reino los ganados vacunos, ovejunos, cabrunos, yeguas, rocines y

45 AGN, Procesos de la Corte Mayor, 8607. 
puercos, apacentarlos y herbajarlos en los términos de Leiza y otras partes, especialmente en Aralar, donde compraban los pastos, yerbas y aguas, libremente sin pagar derechos, excepto los puercos cuando entraban a engordar, pagando un gros (equivalente a 6 maravedís) por cada cabeza mejorada. Por su parte, las Juntas Generales y la Diputación de Guipúzcoa aseguraban que desde tiempo inmemorial -lo cual no parece ser cierto-, desde hacía más de cien años, los vecinos de la provincia, especialmente los de Berástegui y Elduayen, llevaban en verano sus ganados al reino y compraban allí las yerbas y aguas, volviendo en invierno a sus tierras. La provincia exigía que, en caso de pago, únicamente fuese por ganados diferentes a los vacunos y ovejunos. La parte de los tablajeros, sin embargo, mantenía que por cada cabeza de vaca o ganado mayor se pagaba 1 tarja y por cada oveja 10-11 reales castellanos. Algunos de los testigos aseguraban haber visto llevar a los vecinos de Barindano (Améscoas) 50 puercos al Val de Arana en Castilla. Así mismo, desde Álava se introducían en Artavia (Navarra) muchos ganados de todas clases a herbajar. También en esta ocasión, los testigos coincidían en señalar que muchos ganados de Álava, Guipúzcoa y la frontera de Castilla entraban a herbajar en Navarra. Finalmente, el 17 de septiembre de 1534 se sentenció ordenando a los guipuzcoanos que manifestasen sus ganados vacunos cuando entrasen y saliesen del reino, aunque sin pagar más derechos que los correspondientes a las mejoras realizadas, conforme a las nuevas ordenanzas establecidas en 1529, ya descritas, siendo confirmada dicha sentencia el 2 de junio de $1536^{46}$.

La frontera navarro-guipuzcoana también fue testigo del paso de importantes piaras de $\operatorname{cerdos}^{47}$. En 1534, el concejo de Echarri-Aranaz y Ergoyena, a través del bachiller Miguel de Mayoa, Johan de Cubiri y Menant de Suescun, elevaba una denuncia contra Bernat de Cruzat, fiscal y arrendador de los derechos de saca y peaje, en demanda de su libertad para meter y sacar puercos extranjeros a engordar en las sierras de Echarri-Aranaz, de no manifestarlos y de no pagar peajes. El concejo de Echarri-Aranaz permitía la entrada de puercos extranjeros al pasto de roble y haya. Sin embargo, el tablajero de Echarri, Joanes de Echarri, había comenzado a exigirles 1 tarja por cabeza porcina y 2 tarjas por cada carga de trigo. El concejo navarro defendía su libertad de extracción a Guipúzcoa de productos como la sal, trigo y pan navarros ${ }^{48}$. El trasiego y compraventa de ganado porcino entre un territorio y otro era intenso. En 1537 Juan de Ursua, señor de Oiz, denunciaba a Perusqui Eguialdea y Domingo Arguina, vecinos de Areso, exigiéndoles la paga de los perjuicios provocados por detenerle 150-155 puercos que con licencia pasaban de Navarra a Guipúzcoa. Los ocho o nueve porquerizos de Ursua intentaron pasar la piara de puercos hacia Guipúzcoa en diciembre, concretamente en Navidad, por Leiza para llevarlos hasta Eibar. Sin embargo, en ese punto dieciocho vecinos de Areso, al servicio del señor de Ezcurra, apresaron a los puercos con sus lanzas y ballestas, lanzándoles injurias, haciéndoles fuerza y maltratando al ganado; de hecho, mataron algunas cabezas. Los mencionados individuos tuvieron retenidos los puercos día y medio en Areso, donde les dieron de comer dos cargas de cebada, lo que les supuso un gasto de 10 tarjas por

\footnotetext{
${ }^{46}$ AGN, Procesos de la Corte Mayor, 8890 y CO_DOCUMENTOS, Caja 180, № 57.

47 Moraza Barea, "La trashumancia desde el sistema ibérico", pp. 221-238.

48 AGN, Procesos de la Corte Mayor, 26954.
} 
cada arroba. A ello se unió el mantenimiento de los mencionados porquerizos, a razón de 8 tarjas cada uno, además de un jornal de 4-5 tarjas diarios cada uno. Los acusados vendieron la mayor parte de los puercos en Tolosa, Azpeitia, Azcoitia y otras partes. Finalmente, el 14 de agosto de 1537 se sentenció a favor de Ursua, condenando a los acusados a 70 carlines cada uno ${ }^{49}$.

En 1539 Bernat de Cruzat, arrendador de las tablas y fiscal, elevaba causa contra varios vecinos de Echarri-Aranaz por extracción de ganados de cerda. Si bien entre los acusados estaban también Domingo de Erdocia, alcalde, Miguel de Araina, Miguel de Don Sancho, María de Aguerre, y Joanes el sastre, únicamente se ejecutó sobre Luis de Berástegui, Juanot de Peru Juaniz y Domingo de Hulayar un total de 235 groses por 47 ganados de cerda que habían sacado en septiembre de ese año sin manifestar del reino de Navarra hacia Guipúzcoa. Los acusados alegaban que los vecinos de Echarri tenían privilegios para sacar ganado fuera sin pagar derechos. Finalmente, a Luis de Berástegui se le ejecutaron 60 groses por 12 cabezas, a Domingo de Hulayar 75 groses por 15 cabezas y a Peru Juaniz 100 groses por $20^{50}$. Ese mismo año, Juanot de Elizondo denunciaba a Bernat de Cruzat por el cobro de ciertos derechos. Juanot de Elizondo, notario de Elizondo, actuó como fiador para los frailes del monasterio premonstratense de Urdax, quienes extrajeron del reino para llevarlos a Guipúzcoa 120 puercos, por los que debía haber pagado 2 tarjas por cabeza; sin embargo, llevaba cinco años sin querer pagar. Dos mulateros de Elizondo, Sancho de Sumusu y Martincho de Zozaya, se los quisieron comprar para llevarlos a Guipúzcoa a venderlos, pero no accedió. Finalmente, Eneco Sanz de Datue, vecino de Elizondo, llevó los puercos a Guipúzcoa con Johanes Esulino, vecino de Urdax ${ }^{51}$.

El trasiego de ganado entre el reino de Navarra y la provincia de Guipúzcoa se mantuvo a lo largo de la Edad Moderna. En 1542 sendas reales órdenes del Consejo de Navarra a los tablajeros de las tablas fronterizas con Guipúzcoa, daban licencia para extraer a Guipúzcoa hasta un total de 100 cabezas de bueyes y vacas. La primera fue otorgada el 17 de abril a los tablajeros de Echarri-Aranaz y Alsasua y la segunda el 17 de octubre a los tablajeros de Leiza, Betelu y Gorriti, a pesar de la prohibición existente y debido a la extrema necesidad, dando licencia para introducir en Guipúzcoa hasta 100 cabezas de buey y vacas, con condición de que fuesen de la Tierra de Burunda, Tierra de Echarri-Aranaz y Tierra de Araiz: Echarri-Aranaz aportaría 20 cabezas, Alsasua 30 cabezas, Leiza 16 cabezas, Betelu 16 cabezas y Gorriti 18 cabezas $^{52}$.

\section{CONCLUSIONES}

Durante los siglos XII y XV algunas instituciones eclesiásticas navarras, que contaban con una extensa cabaña ganadera, desarrollaron una trashumancia de largo recorrido entre sus pastos de invierno y de verano, uniendo territorios tan alejados

\footnotetext{
49 AGN, Procesos de la Corte Mayor, 130428.

50 AGN, Procesos de la Corte Mayor, 456, 457 y 459.

51 AGN, Procesos de la Corte Mayor, 36182.

52 AGG-GAO, JD IM, 1/10/12.
} 
como el Pirineo navarro y la costa guipuzcoana o labourdina. Esta trashumancia tuvo como protagonistas los seles y propiedades de dichas instituciones, adquiridas entre los siglos XI y XIV, y consolidadas posteriormente. En ninguno de los casos, los privilegios adquiridos incluían los montes comunales de las zonas de acogida, que, sin embargo, pudieron disfrutar parcialmente, gracias a la firma de convenios con las instituciones locales. En todos los casos, se imponía el pasto "de sol a sol", lo que implicaba que los bustos de las instituciones mencionadas podían disfrutar de todos los pastos a su alcance desde los seles de albergue; sin embargo, una vez puesto el sol, debían volver a sus cabañas, no pudiendo disfrutar de noche de los pastos comunales. En Guipúzcoa la trashumancia de largo recorrido entre pastos comunales no se generalizó prácticamente hasta el siglo XVIII, primando hasta entonces traslados de corto recorrido, de carácter trasterminante ${ }^{53}$.

No obstante, si existió trashumancia de largo recorrido de pequeños rebaños, pertenecientes a propietarios particulares, que firmaban contratos con otros particulares de jurisdicciones alejadas a las suyas, para albergarlos en verano o invierno ${ }^{54}$. El caso de la catedral de Pamplona o de la colegiata de Roncesvalles es una situación intermedia, puesto que eran grandes propietarios y poseían tierras propias tanto en área de invernada como de estío, lo que les permitía realizar el trasiego por encima de límites y limitaciones jurisdiccionales concejiles. A pesar de ello, prácticamente desde el siglo XIII, los conflictos con los vecinos e instituciones de los lugares de invernada fueron continuos. Si bien dichos bustos disfrutaron de prados y pastos de su propiedad, en los que las instituciones y habitantes locales no tenían participación, como terrenos particulares que eran, el proceso de consolidación territorial y el avance demográfico que se produjo durante ese período, sobre todo a partir de mediados del siglo XIV, hizo que los ataques, excesos, usurpaciones y ocupaciones fuesen cada vez más comunes. Ante ello, dichas instituciones se vieron obligadas a, por un lado, ceder la gestión directa de sus propiedades, delegándola en particulares o en entidades locales, de las que cobrarán diferentes rentas, en calidad de censos, y, por otro, a detener el régimen de trashumancia hacia los pastos invernales guipuzcoanos y buscar otros nuevos o intensificar los que ya se poseían en otras latitudes.

En el caso concreto de Roncesvalles, sin embargo, sus bustos seguirán aprovechando su red de propiedades y seles para invernar en zonas guipuzcoanas -Irisarri (Andaza e Idia), en Usúrbil- o cercanas al territorio guipuzcoano -Anizlarrea, en Goizueta-, a fin de repastar y herbajar sus rebaños. Precisamente, esta práctica comenzó a ser muy habitual desde mediados del siglo XV, coincidiendo con la expansión ganadera que se produjo en todo el arco cantábrico. El crecimiento de algunas cabañas locales, la escasa disponibilidad de pastos, por lo exiguo de los términos jurisdiccionales, y la fluida red de comercio terrestre existente entre los territorios peninsulares -permitiendo a la carne o el pescado guipuzcoanos llegar incluso hasta el reino de Aragón-, hicieron que se desarrollase un trasiego anual y estacional, entre pastos de verano e invierno, principalmente relacionado con el ganado vacuno y porcino, con la finalidad de repastar, herbajar y mejorar los ganados, tanto guipuzcoanos

53 Aragón Ruano, La ganadería guipuzcoana, pp. 29-90; DíAZ DE DuranA, "Economía ganadera”, pp. 47-48.

54 Aragón Ruano, La ganadería guipuzcoana, pp. 144-152. 
como navarros. En numerosas ocasiones, esa estancia estacional era aprovechada por los propios vaquerizos y guardas o por los carniceros de las localidades guipuzcoanas cercanas a la frontera navarra para realizar interesantes compraventas de ganado y productos lácteos. Dicho trasiego estuvo inmerso en una importante conflictividad, tanto jurisdiccional como fiscal, pues hubo, sobre todo por parte de las instituciones navarras, un intento fiscalizador y controlador de la actividad, endémicamente afectada por prácticas ilegales y de contrabando.

\section{BIBLIOGRAFÍA}

Alberdi Lonbide, Xabier y ArtetXe Fernández, Oihana, Orioko baserrien gidaliburua. Historia eta paisaia, Orio, Ayuntamiento de Orio, 2011.

Álvarez Morales, Antonio, "La Hermandad de Vitoria, Álava, Guipúzcoa, Val de Lana y otros en defensa del Reino de Navarra (1368-1369)", en Vitoria en la Edad Media. Congreso de Estudios Históricos, Vitoria, Ayuntamiento de Vitoria-Gasteiz, 1982, pp. 341-347.

Aparicio Rosillo, Susana, "La cabaña de las órdenes religiosas en el Pirineo. Los intereses ganaderos de las órdenes religiosas en Ultrapuertos, Labourd, y el Béarn durante los siglos plenomedievales", RIEV, 59, 1 (2014), pp. 8-35.

Aragón Ruano, Álvaro, El bosque guipuzcoano en la Edad Moderna: aprovechamiento, ordenamiento legal y conflictividad, San Sebastián, Sociedad de Ciencias Aranzadi, 2001.

Aragón Ruano, Álvaro, La ganadería guipuzcoana durante el Antiguo Régimen, Bilbao, UPV, 2009.

ARIGita y Lasa, Mariano, Historia de la imagen y santuario de San Miguel de Excelsis, Pamplona, Imprenta y Librería Lizaso Hermanos, 1904.

Artola, Miguel, Historia de Donostia-San Sebastián, San Sebastián, Editorial Nerea, 2000.

Ayerbe Iribar, María Rosa, "Sobre el hábitat pastoril y la pasturación de ganado en el valle del Urumea (Guipúzcoa)", Acta Historica et Archaeologica Mediaevalia, 7-8 (1986-1987), pp. 311-320.

Ayerbe Iribar, María Rosa, “La Unión o Mancomunidad de Enirio y Aralar. Un caso modélico de montes comunales intervenidos por el Servicio Forestal de la Diputación de Gipuzkoa", Boletín de la Real Sociedad Bascongada de Amigos del País, LXI, 1 (2005), pp. 5-136.

Ayerbe Iribar, María Rosa, "La hermandad de frontera ente Álava y Guipúzcoa: el capitulado contra malhechores del Puerto de San Adrián de 1450", Boletín de la Real Sociedad Bascongada de Amigos del País, LXIV, 1 (2008), pp. 369-386.

Barquero GoÑI, Carlos, La orden de San Juan de Jerusalén en Navarra. Siglos XIV y XV, Pamplona, Fundación Fuentes Dutor, 2004. 
Barrena Osoro, Elena, La formación histórica de Guipúzcoa. Transformaciones en la organización social de un territorio cantábrico durante la época altomedieval, San Sebastián, Universidad de Deusto, 1989.

Ciérbide Martiarena, Ricardo, "Conflictos fronterizos entre Navarra, Guipúzcoa y Álava en el siglo XIV", en Vitoria en la Edad Media. Congreso de Estudios Históricos, Vitoria, Ayuntamiento de Vitoria-Gasteiz, 1982, pp. 449-470.

Crespo Rico, Miguel Ángel, Cruz Mundet, José Ramón y Gómez Lago, José Manuel, Colección Documental del Archivo Municipal de Rentería, Tomo I (1237-1470), Donostia, 1991.

Crespo Rico, Miguel Ángel, Cruz Mundet, José Ramón y Gómez Lago, José Manuel, Colección Documental del Archivo Municipal de Rentería. Tomo II (1470-1500), San Sebastián, Eusko Ikaskuntza, 1997.

Díaz de Durana, José Ramón y Fernández de Larrea, Jon Andoni, "Economía ganadera y medio ambiente. Guipúzcoa y el Noroeste de Navarra en la Baja Edad Media", Historia Agraria, 27 (2002), pp. 43-64.

Díaz de Durana, José Ramón y Fernández de Larrea, Jon Andoni, "La frontera de los malhechores: bandidos, linajes y villas entre Álava, Guipúzcoa y Navarra durante la Baja Edad Media”, Studia Histórica, Historia Medieval, 23 (2005), pp. 171-205.

Furundarena Salsamendi, José Javier, "Hondarribiko toponimia", Onomasticon Vasconiae, 23 (2002).

GoÑ Gaztambide, José, Catálogo del archivo catedral de Pamplona, Tomo I, Pamplona, 1965.

InSAUSTI, Sebastián, "Situación canónica de las iglesias de San Sebastián en los siglos medios", Boletín de la Real Sociedad Bascongada de Amigos del País, XIX, 4 (1963), pp. 297-313.

Larrañaga Zulueta, Mikel y Tapia Rubio, Izaskun, Colección Documental del Archivo Municipal de Hondarribia. Tomo I (1186-1479), San Sebastián, Eusko Ikaskuntza, 1993.

Larrañaga Zulueta, Mikel, y Lema Pueyo, José Ángel, Colección de documentos medievales del convento de San Bartolomé (San Sebastián) (1250-1515), San Sebastián, Eusko Ikaskuntza, 1995.

Líbano Zumalacárregui, Ángeles y Villacorta Macho, Consuelo, Paisaje rural y explotación agropecuaria. Léxico de los recursos naturales y de la vida cotidiana en el aragonés, navarro y romance vasco (siglo XIII-XVI), Zaragoza, Prensas de la Universidad de Zaragoza, 2013.

Miranda García, Fermín, Roncesvalles. Trayectoria patrimonial (siglos XII-XIX). Pamplona, Gobierno de Navarra, 1993.

Moraza Barea, Alfredo, "La trashumancia desde el sistema ibérico al Pirineo occidental: el pastoreo de ganado porcino entre la sierra de Cameros (Soria-La Rioja) y el País Vasco a fines de la Edad Media", en Aymat CATAfau, Les ressources na- 
turelles des Pyrénées du Moyen Âge à l'époque moderne. Exploitation, Gestion, Appropriation, Presses Universitaires de Perpignan, 2005, pp. 221-238.

Mugueta Moreno, Íñigo, "Las hermandades navarras en la primera mitad del siglo XV: hermandades de frontera y del reino", en Mito y realidad en la historia de Navarra, Pamplona, SEHN, 1998, t. 1, pp. 421-428.

Mugueta Moreno, Íñigo, “Acciones bélicas en Navarra: la frontera de los malhechores (1321-1335)", Príncipe de Viana, Año LXI, 219 (2000), pp. 49-78.

Mutiloa Poza, José María, Roncesvalles en Guipúzcoa, San Sebastián, Caja de Ahorros Provincial de Guipúzcoa, 1976, 3 vols.

Orella Unzue, José Luis, "La Hermandad de Frontera entre Navarra y Guipúzcoa, s. XIV y XV", Príncipe de Viana, Año XLVI, 175 (1985), pp. 463-492.

Ostolaza Elizondo, María Isabel, "La organización eclesiástica guipuzcoana durante la Edad Media", en Actas del Congreso "El Fuero de San Sebastián y su época", San Sebastián, Eusko Ikaskuntza, 1982, pp. 149-192.

VARIOS Autores, Los señores de la guerra y de la tierra: nuevos textos para el estudio de los Parientes Mayores guipuzcoanos (1265-1548), San Sebastián, Diputación Foral de Gipuzkoa, 2000.

Zabalo Zabalegi, Javier, La administración del Reino de Navarra en el siglo XIV, Pamplona, EUNSA, 1973.

ZABALo ZABALEGI, Javier, "El acoso de guipuzcoanos y alaveses a los ganaderos navarros: la «frontera de los malhechores» entre 1280 y 1349", Príncipe de Viana, Año LXVI, 234 (2005), pp. 53-109. 